\title{
Erratum to: A new ecological control method for Pisha sandstone based on hydrophilic polyurethane
}

\author{
LIANG Zhishui $^{1}$, WU Zhiren ${ }^{2}$, Mohammad NOORI ${ }^{3}$, YANG Caiqian $^{1 *}$, YAO Wenyi ${ }^{4}$ \\ ${ }^{1}$ School of Civil Engineering, Southeast University, Nanjing 210096, China; \\ ${ }^{2}$ School of the Environment and Safety Engineering, Jiangsu University, Zhenjiang 212013, China; \\ ${ }^{3}$ International Institute for Urban Systems Engineering, Southeast University, Nanjing 210096, China; \\ ${ }^{4}$ Key Laboratory of Soil and Water Loess Process and Control on Loess Plateau of Ministry of Water Resource, Yellow River \\ Institute of Hydraulic Research, Zhengzhou 450003, China
}

Published online: 22 August 2017

(C) Xinjiang Institute of Ecology and Geography, Chinese Academy of Sciences, Science Press and Springer-Verlag GmbH Germany 2017

\section{Erratum to: J Arid Land (2017) 9(5): 790-796 \\ doi: 10.1007/s40333-017-0102-7}

In this Erratum, we correct the family name of the first author that was spelled as "LINAG" in Journal of Arid Land and the correction is "LIANG".

The online version of the original article can be found under doi: 10.1007/s40333-017-0102-7. 